\title{
Use of monologues, games and problem solving activities for development of speaking skills
}

\author{
Klaudia Pavlikova \\ Constantine the Philosopher University in Nitra; klaudia.paulikova@ukf.sk
}

\begin{abstract}
Oral communication is one of the most important aspects of information exchange between individuals. Considering teaching of foreign languages, it is evident that the development of speaking covers quite an extensive part of the foreign language learning process. The study presents the importance of speaking within mastering a foreign language on a theoretical basis and provides an insight into real teaching-learning environment. The practical part of the study introduces the implementation of three activities into the teaching process monologues, games and problem solving activities. With the aim of finding possibilities for improving the quality of the teaching process in the terms of the development of speaking, action research is used as the tool for data collection and evaluation. The findings and the results of the study demonstrate how the three activities develop speaking and what benefits their use brings to the foreign language classes.
\end{abstract}

Keywords: foreign language education, speaking, monologues, games, problem solving activities, action research

\section{Introduction}

The ability to communicate in a foreign language has been gaining more and more importance and popularity in the recent decades. The demand on knowing a foreign language is getting higher, especially when it comes to English, the global language. The modern era of education provides us with countless possibilities on how to acquire the language in the most efficient ways. There are numerous approaches, methods and special techniques developed for the purposes of successful and effective foreign language education.

Considering speaking in the foreign language, it can be stated that it covers the basis of everyday communication. Even though all the four communicative skills are essential in order to develop proper and complete communicative competence, speaking is considered as the core skill by many. The reason can be found in the great demand of communication as the most important aspect of language knowledge in the modern world (Howatt \& Smith 2014).

\section{Nature of speaking}

Due to the fact that the vast majority of conversations is carried out exclusively by oral communication, it is clear that speaking is one of the most important aspects of language to be mastered. Brown and Yule (1983) note two basic functions of speaking - transactional and interactional. The transactional function, as the authors represent it, aims at transferring specific information (facts and knowledge) to a desired audience. It is the transactional function of language that allows any cultural development (religious, social, trading) to occur. Socializing and maintaining relationships is done under the interactional function of speech. It is the language used for everyday communication, negotiation of relationships, turn taking and time filling (ibid.). Richard (2008) remarks that in talk as transaction the main focus is on the message. In talk as interaction, however, the focus is on the speakers and the way they wish to communicate their message. Considering the nature of the teaching process as it comes to foreign language education, the teachers are aiming at achieving both transactional and interactional function of speaking (Thornbury 1995).

It is important to identify four mental processes - conceptualization, formulation, articulation and self-monitoring, which take place when producing an utterance. The production begins with conceptualization, which is a sincere planning of the content desired to be communicated. This involves taking all the circumstances (e.g. other participants, changes in the course of conversation) into account and being able to adjust the concept to possible changes. The next step, formulation, involves preparing and formulating the message into meaningful units of words, expressions, phrases and sentences (Levelt 1989). It is at the stage of formulation, as Thornbury (1995) explains, when speakers make decisions 
about the stress and intonation of the units to be communicated. Following formulation, the process of articulation takes place. It is the process of physical release of the message, which engages the movement of articulatory organs in order to produce sound. Self-monitoring, at last, marks the ability of speakers to monitor themselves, thus having the opportunity of self-correction in the case of making any mistakes (Levelt 1989). Carter and Nunan (2001) and Thornbury (1995) further add that the success of these processes depends merely on automation. Due to the fact that human beings are not able to focus their attention on every single aspect of their speech production, it is essential that the four formerly mentioned processes are automated to such a great deal as it is possible, because lack of it may cause difficulties in speech. It is no surprise, as Ur (1996) explains, that speakers of foreign languages are experiencing much more difficulties in producing fully valuable speeches, as the switching between mental processes while speaking in a foreign language is not as automated as in their L1.

It becomes quite clear, however, that the nature of speaking is not only affected by the mental processes, but also by context. Bygate (1987) and Long and Doughty (2011) refer to speaking as having a reciprocal dimension, i.e. of existing among more than just one participant. It mostly occurs simultaneously and the participants are able to contribute to the flow of the conversation freely and at any time. They either have equal rights for speaking, or are in a sub-ordinate position to others. The oral communication, therefore, is much more dynamic and unpredictable than the written one (Thornbury 1995).

Furthermore, speaking is mostly a face-to-face occurrence. Providing that the speakers have the ability to see each other, the communication becomes easier, as there are many paralinguistic means to be used in order to communicate a meaningful and well understandable message, such as physical movements, gestures or face expressions (Carter \& Nunan 2001).

The use of expressive devices is also part of features of speaking. Speakers, as Luoma (2004) explains, use various specificities of speech connected to sound - change of pitch, stress, vary volume or intonation. What is more, they often add emotional load to their speech, which together with the use of paralinguistic and physical means contributes to a well comprehensible, dynamic and rich utterance (Harmer 2001).

Richards and Burns (2012) refer to connected speech as another feature of spoken utterance. Speaking as such not only requires the proper use of phonemes individually, but also to connect them into a real, fast speech. This includes assimilation, elision, linking and the use of weak forms. Even though it is a natural occurrence for native speakers of English, connected speech may be difficulty causing for non-native speakers. The reason for this is seen in the fact that non-native speakers are not aware of all the context due to not being familiar with all the expressions of the language, therefore they are not able to guess the meanings so well as natives do (Harmer 2001).

Carter and Nunan (2001) furthermore mark speaking as a phenomenon, which happens in real time. Speakers are required to decide what message to communicate without long hesitations and are not allowed to take extra time for checking and correcting their message.

In addition to that, a spontaneous, real time speech may possess specific lexis and grammar. There is a need to consider the significant difference between spoken and written language, as the former is organized at the level of "self standing clause-like chunks, assembled according to incremental add-on strategy" rather than sentences, which are a typical organizational form of writing (Richards \& Burns 2012: 200). There are certain lexical expressions and phrases, which are more commonly used in spoken interaction, than in the written one. As examples expressions of agreeing, disagreeing, surprise or shock may be mentioned (Harmer 2001).

\section{Teaching speaking}

Considering teaching speaking, it is very rare to deal with one language skill at a time only, as the four skills are integrated. The education of languages should reflect that, as well, and integrate all the language skills into the teaching process in order to be as effective as possible (Hinkel 2010). Moreover, there is a tendency to consider speaking as a medium for communication rather than a language skill to be taught (Long \& Doughty 2011). Speaking as such in the average classroom is very often restricted to check comprehension. Thus activities that would develop thinking and improve practical use of the 
language in communicative situations are almost completely omitted (Fisher, Frey \& Rothenberg 2008). Despite that learners of foreign languages find speaking as the most important skill to be mastered and also the most difficult one to be learned (Gani, Farjina \& Hanifa 2015). Gondová (2013) explains that the learners of foreign languages are good at taking tests and passing exams but they lack the ability to use the foreign language efficiently in real situations. They often have difficulties in speaking, which may originate in lack of confidence, problems with accuracy and fluency, or insufficient background knowledge about the language. This makes them afraid of speaking and causes them not using the foreign language as effectively as they could (Pauliková 2017). Therefore the whole process of teaching should be concerned not with how to make the learners interested in speaking, but rather how to find the most efficient ways to teach it (Richards 2008). Communication is the foremost goal to be reached; therefore learners need to be provided with sufficient circumstances for the ability of expressing their attitudes, opinions and feelings (Kováčiková \& Gajdáčová-Veselá 2016).

There are plenty techniques and types of activities that are offered under various teaching methods and approaches. Their choice may depend on many things. On one hand it may be the most frequently used teaching approach, which determines the overall flow of the education process, on the other hand it can be determined by the national curriculum, school or even teacher, who decides about the most appropriate and effective ways of teaching for a successful educational process (Harmer 2012).

The success of the education of foreign languages does not however solely lie in the use of one or another method. Scrivener (2005) admits that teachers nowadays use a mixture of approaches and techniques, which are chosen and adjusted according to their own experience in the classrooms. As the main aims of teaching techniques are motivation, help in the development of critical thinking and facilitation of the learning process in order to prepare the learners for the ability to use the language beyond the borders of the classroom (Pokrivčáková 2013), it is vital for the teachers to find and implement such approaches in their foreign language education that meet these criteria and are beneficial for the development of the learners' skills.

When it comes to the use of specific activities for the development of speaking in the foreign language, it is important for the teachers to define, whether the techniques meet the criteria of a successful activity. Ur (1996) defines these in high participation, adequate language level, a lot of talking and high motivation among the participants. Moreover, it is important to set the main objectives of the activities. As Brown (2004) and Kováčiková and Gajdáčová-Veselá (2016) state, the use of approaches, techniques and activities for speaking should be based on a precise planning of the field of focus - the control over the activity, whether it is aimed at speaking individually, in pairs, or groups and if the attention is paid on the practice of accuracy, fluency or other feature of speech in a foreign language.

\section{Monologues, games and problem solving activities}

There is a great variety of activities designed for developing speaking. In an effective teaching process, learners should not only retrieve formerly gained knowledge but the activities should also lead to success in real communication beyond the class (Harmer 2012).

Monologues and presentations are defined by individual oral work of students and are aimed at practicing all the areas of the language system. They not only enhance the use of all the language skills but are also confidence building. They require a clear task and time for preparation, which is followed by the performance, often extremely time consuming, though (Harmer 2012). Integration of the four skills is seen as a great advantage by Al Issa and Al Qubtain (2010), as well. They note that besides speaking, there are many more ongoing processes. The audience listens to the speaker's utterance and very often they read the instructions or even make notes or write questions for further discussion. Giving oral presentations is a great way to "encourage the presenting students to practice meaningful oral English" (ibid: 229).

Problem solving activities present a "problem" to the learners, who are, either alone, in pairs, groups or as a whole class required to find solution to it. These activities are constructed for the learners to enhance their critical thinking in the given language. In addition to that, they are very beneficial as the learners are forced to think in the target language, which improves their overall communicative competence to a great deal (Harmer 2001). Reid and Kováčiková (2018) describe certain kinds of 
problem solving activities as improving divergent thinking, enhancing creativity and developing higher level thinking skills.

"Games are effective tools for learning because they offer students a hypothetical environment in which they can explore alternative decisions without the risk of failure. Thought and action are combined into purposeful behaviour to accomplish a goal. Playing games teaches us how to strategize, to consider alternatives, and to think flexibly" (Martinson \& Chu, 2008: 478). Being one of the most attractive means of practicing language for the learners, games are considered to be advantageous in FLE for more reasons. With their possibility to be performed in pairs, groups or even as a whole class, they not only help in the development of the speaking skill on many levels, but also act therapeutically, which can be considered as an extra advantage (Harmer 2001). The variety of games available for practicing speaking is huge. There are verbal games, board games, memory games, cumulative games, creative games, etc., all with the function of teaching and amusing (Pokrivčáková 2013).

\section{Research}

The main goal of the researcher was to investigate the phenomenon of the development of speaking by the three previously mentioned techniques in a real teaching environment. For that purpose, action research was conducted at a local language school with adult learners. There were two main aims that were highlighted as follows.

1. To find out what ways for improvement of the teaching process of the development of speaking the three activities -games, monologues and problem solving activities offered in the teaching process.

2. To find out whether the activities implemented were beneficial for both the learners and the teaching process and whether there were any suggestions for further improvement of the lessons.

The research questions were, therefore, stated as follows:

1. How may the speaking skill of learners of English be improved by the use of monologues, games and problem solving activities?

2. What are the reflections on the collected data and suggestions for future improvement?

\section{Action research}

The investigation itself was divided according to four main phases - planning, action, observation and reflection.

\section{Planning}

The initial planning phase clarified the most crucial points of the study - the reason for conducting action research, the fields for improvement and the concrete, specific actions that needed to be carried out to be successful in the investigation. The main reason for investigating the issue of developing speaking by action research was the intention of improving the quality of the teaching process. Despite the fact that the learners of English were improving in their studies and the overall teaching process was found appropriate and successful, a long term observation of the lessons had revealed that very often the learners were not challenged enough to do their best. Moreover, the practice that was provided by the textbooks was not enough, offering just a limited number of activities for improving speaking. The very important aspect of successful language teaching process - the motivation of learners, was therefore missing.

\section{Action}

Based on the information from the first phase the main action was conducted. There were three activities chosen for the investigation - monologues, games and problem solving activities. The activities were implemented into the lessons of English with the aim of finding out whether they were beneficial for the development of speaking skill. The action lasted for the amount of two months and the activities were implemented repeatedly. There were two groups of learners chosen for the investigation and the activities were adapted according to the course book and the corresponding topic of the lesson. 


\section{Observation}

The observation was done simultaneously with the action. While implementing the activities into the lessons, the observer carried out an observation of all the happenings. The information collected were noted down for a subsequent assessment of the data. The observation itself was concerned with the activities that were implemented, whether the learners found them interesting, motivating and challenging for speaking, whether the activities developed their confidence, complexity of speech or any of the aspects such as accuracy and fluency. The observation also focused on whether the learners switched to their mother tongue while performing. Subsequently to the observation, the collected data were evaluated.

\section{Reflection}

The last phase of the action research was processing and evaluating the collected data. The main aim was finding out whether the activities used in the action phase were successful and beneficial. The reflection included an interview, which was incorporated into two lessons with all the learners. After the interview the collected data were evaluated and the conclusion was made.

\section{Research sample}

The research sample was chosen according to purposive sampling. There were two groups of adult learners chosen for the study. Both of the groups attended English lessons 2 times a week for 90 minutes in a local language school situated on the west of Slovakia. Group A consisted of 6 learners that were attending an "elementary" course with the proficiency level A2. Group B consisted of 6 learners that were attending an "intermediate" course with the proficiency level B1.

\section{Implementation of the activities into the teaching process}

The four phases of the action research were thoroughly planned in order to collect valuable and credible data. The whole course of the investigation lasted for two months and its main aim was finding possible ways for improving the development of speaking skill of the two groups of learners. The activities were implemented repeatedly and their duration was $20-25$ minutes on average.

\section{Games}

Games have been a part of the teaching process within the language school for a longer period of time. There are two main reasons why they were implemented into the research procedure, as well. First of all, as the data in the theoretical part showed, games offer a perfect basis for practising accuracy. The second reason was that due to the fact that games are "played" and offer a funny and relaxing atmosphere, they do not evoke a feeling of studying hard. The main aim of the games was practicing the target language, thus training accuracy as much as possible. One of the partial goals of the researcher was finding out whether the games were beneficial in any other aspects of improvement and whether they were able to contribute to the development of speaking in a foreign language in any other way than practicing already mastered linguistic structures.

\section{Action and observation}

The course of the activity went very well as all the learners had practiced playing games before. They were handed a sheet of paper with a board game on it (for the group A it was 'Where were you' for practicing the past simple of the verb be; for group B it was "Conditionals race " for the practice of zero and first conditional, both games retrieved from Speak Out Teacher's Resource book). They were divided into groups of three and given counters and a dice for each group. Their task was to go through the games and at every square they got to fulfil the given task - answer a question or complete a statement correctly. The first who got to the finish square was the winner.

The games were very challenging as all the learners wanted to win. They were completing the tasks and moving closer to the finish willingly and with joy. They were all paying attention to creating accurate structures, which was not very difficult for them as they had acquired these in their previous studies. 
Both of the groups were equally successful in completing the games and in doing well in creating meaningful sentences with little or no mistakes. They did it with confidence and the more squares they completed, the more spontaneously and easily they forwarded in taking their turns to answer.

\section{Findings and reflection}

Games were perhaps the most motivating and challenging activity used throughout the study. The learners not only had the chance to practice the patterns and structures on their own but were exposed to input of information from the other participants of the game, as well, thus having the responsibility to check and correct their possible mistakes. The learners paid extra attention on producing accurate sentences, therefore the chance to switch to mother tongue was completely eliminated, which can be considered as one of the greatest advantages. On the other hand, because the learners were taking turns and producing short utterances, the possibility to develop their fluency was decreased.

Referring to the difficulties in speech production, it was clarified that games, besides of being very motivating and confidence building for speaking, also worked as great source for improving accuracy without switching into the mother tongue. The list of all benefits and deficiencies is depicted in the following table.

Table 1: Benefits and deficiencies of games.

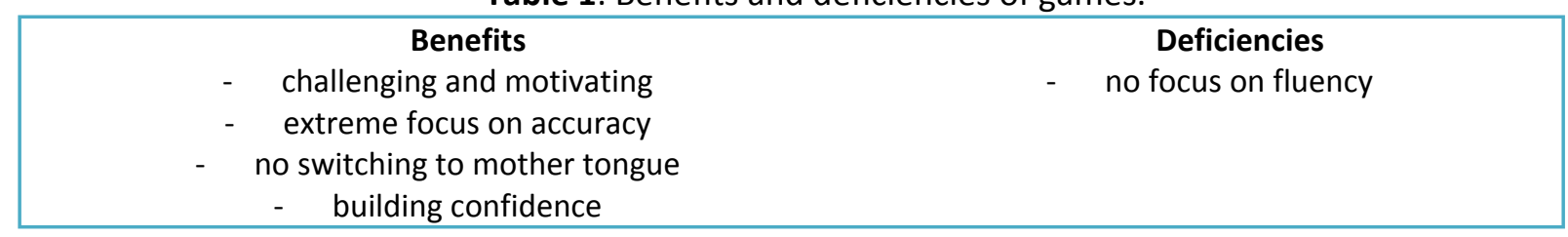

\section{Problem solving activities}

The activity of problem solving was introduced to the lessons in the language school for the first time. Many sources claim that they are a great source for improving thinking in the target language, which provides great help for development of general language competences of learners. The researcher's aim was to find out whether problem solving activities were beneficial for the development of speaking in a foreign language and whether the learners were able to think and cooperate with others in the target language in order to find a solution for a given task. A complementary aim was to find out if the activity was useful for the development of the speaking competence in the means of decreasing learners" difficulties in speech.

\section{Action and observation}

The learners were handed a problem solving task on a sheet of paper. It was the same task for both of the groups and the name was „Musical Recital', found in Pokrivčáková (2013) (original source: www.brainbashers.com). The learners were asked to work in pairs and read the tasks to each other. Their task was, according to the hints given in notes, to find out the correct order of people, their musical instruments and the composers they performed.

The students started reading the tasks to each other aloud. They kept reading all the hints all over again in order to find the solution of the puzzle. As they were reading, they were repeating the key information to be able to move forward in solving for many times. They were also noting down the most important information in English and discussing the possible answers with their partners. Even though the majority of learners enjoyed the activity and had no difficulties to solve it (it took them five minutes on average), some of the learners seemed to struggle with it and not find it satisfying at all. Both groups of learners did well in the activity, except two learners from Group A and one from Group B, who could not keep the pace with the other learners. Even though they managed to fulfil the task and solve the problem, it took them much more time than their classmates and seemed very frustrated while working. 


\section{Findings and reflection}

The outcomes show that the problem solving activity was not found attractive for all the learners. Moreover, due to the fact that the language used in it was very limited with a repetitive tendency, it can be stated that it was not the best solution for developing accuracy, fluency, confidence, or complexity of speech in a given language.

It must be stated, on the other hand, that the learners used solely English while performing the activity. They were reading, repeating, noting down and discussing with their partners - all in the target language. For this reason it can be assumed that these kinds of activities help in the development of thinking in English. Moreover, the fact that the learners were asked to work in pairs made them cooperate and search solutions together, which provided them with opportunities for critical thinking. The advantages of problem solving, as result, lie in the development of thinking in the target language and helping in thinking critically, which is one of the key factors to overcoming problems with speaking. The findings are also depicted in the table below.

Table 2: Benefits and deficiencies of problem solving activities.

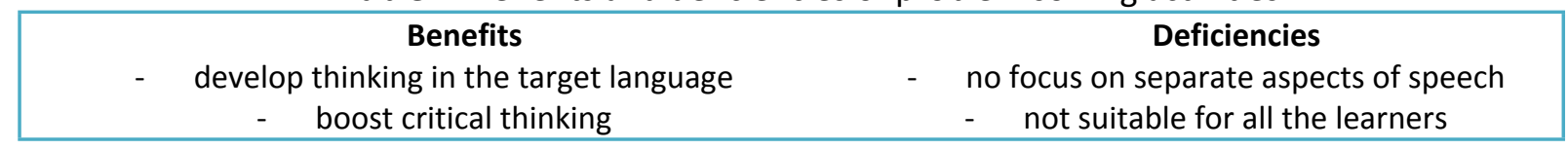

\section{Monologues}

Giving shorter or longer speeches in a person's life is a natural occurrence. Being able to do it also in a foreign language requires either good speaking skills background knowledge of the language, or enough preparation. Monologues are manifold in their nature. Learners may talk about different topics on their own for a given amount of time, give presentations or lectures on various subjects, or even perform something. Provided that the learners of foreign language are given enough time and resources for preparation, even the ones at the lowest proficiency levels can give good quality speeches. The implementation of monologues and presentations was completely new for the learners, as these activities had not been used before due to their extremely time consuming nature. By implementing them into the course of study the researcher aimed at finding out to what degree the learners were able to give meaningful, fluent speeches and whether the activity was providing any help in overcoming difficulties with fluency, accuracy and confidence in speaking.

\section{Action and observation}

The researcher provided all the learners with various pieces of information (about holidays of various countries, information of artists, cuisine, etc.) in printed form. Both of the groups were provided materials corresponding to their own language abilities. The researcher explained the task. The learners needed to read their articles and summaries and prepare a short few minute presentation about the given topic. They were explained that they all had a different topic to be summarized and their main task was retelling the read information to their classmates. The time for preparation was approximately ten minutes and the learners were allowed to take notes and use dictionaries for assistance with unknown words or phrases (both printed and online versions, which the students used on a daily basis).

During the preparation the learners of both groups were reading their papers attentively and highlighting all the information they considered important. They were using the dictionaries provided and taking notes to their notebooks. When the ten minute limit for preparation was over, they were asked one by one to present their topic to the rest of the class.

The presentations went very well. The learners gave their speeches one by one. The stronger ones did it without reading their notes; some however, used their papers for assistance. They all were describing the issues they had been given at the beginning with pleasure and interest. They were paying extra attention on saying everything important they had come to so that their classmates would understand the main idea of their speech. They concentrated on saying everything accurately and in as a complex way as possible. They did it confidently and were very satisfied, when, after finishing they were praised by the teacher for their good work. The teacher did not intervene in the process of giving the 
presentations at all. After finishing, one or two follow up questions were asked, which the learners answered without any difficulties.

The presentations in Group A went as well as those in Group B, because all the articles they had been given were equivalent to their level of proficiency. In both of the groups, however, were two weaker students, who needed more time for expressing their thoughts with a slower speed of speech than the others had. Despite that fact, they all did very well in the presentations and were happy to perform in English for such a long time.

\section{Findings and reflection}

Even though the activity was very time consuming (ten minutes overall preparation and three to five minutes of presentation per student) it must be stated that it was very successful from various viewpoints. Due to the fact that the learners had time for preparation, their utterances were smooth, fluent and they could perform with confidence without feeling stressed about what to say. As both the input and output of information happened in English, the learners were encouraged to think in the target language (which was also observed by the researcher - learners were mumbling and whispering in English while taking notes and preparing their speeches). Moreover, they did not switch to mother tongue, at all. They concentrated on creating meaningful and accurate sentences, therefore the activity showed to be beneficial for developing accuracy, as well. Lastly, the learners were exposed to new information, which provided them with new opportunities to widen their background knowledge about certain topics in the target language.

As a disadvantage the time consuming nature of the activity must be mentioned. The length of it would not be a problem alone, but some of the learners (especially those, who had already performed), got bored very quickly and did not pay attention, even when they were asked to.

Summing up all the previously mentioned facts, it can be stated that monologues and presentations are very beneficial for the development of speaking and elimination of difficulties. They not only develop fluency and accuracy in the target language, but also boost confidence, improve the overall complexity of speech and provide the learners with possibilities to acquire language from various, new sources of information. The benefits and deficiencies are also listed in the subsequent table for a more detailed view.

Table 3: Benefits and deficiencies of monologues.

\begin{tabular}{|cc|}
\hline Benefits & Deficiencies \\
$-\quad$ improve thinking in English & no use of mother tongue \\
$-\quad$ improvement of fluency & extremely time consuming \\
$-\quad$ Improvement of complexity of speech & develop accuracy \\
$-\quad$ Enhancement of confidence \\
Good exposure of new information in the \\
target language
\end{tabular}

\section{Conclusion}

Considering the activities that were implemented into the teaching process, it can be stated that the whole action research was very successful. The great variety of the opportunities for speaking made the lessons of English not only more challenging and motivating for the learners, but also added value to the teaching process itself, as there were numerous new possibilities for developing speaking. Games and monologues were found extremely beneficial for the development of accuracy in speaking. Monologues also improved the fluency in speech, which is also a vital aspect of the speaking skill. All the implemented activities were found to be improving confidence of the learners, which is important not only for their inner good feeling of performing well, but also for the overall quality of their performance. Problem solving activities were best for developing thinking in the target language. The overall complexity of speech was found to be developed by the use of monologues. To conclude, it may be 
assumed that by implementing these activities into the teaching process on a regular basis it is highly possible that it will contribute to eliminating speaking problems the learners are likely to experience throughout their language studies. Moreover, the overall performance of the learners can be improved.

\section{Reflections and suggestions for further improvement}

The observation of the lessons revealed that the previously mentioned activities helped in improving the effectiveness of the teaching process and the overall performance in speaking. The next step was investigating the issue from the viewpoint of the learners themselves. For this reason an interview was conducted, which represented the last phase of the action research. The main aim was to find out whether the learners were satisfied with the three activities and whether there were any suggestions for the further improvement in the quality of the teaching process. Their reflections were process into a table for a better overview.

Table 4: Suggestions for future improvement.

Participants' suggestions for future improvement
- Implement discussions about real life topics into every lesson
- Use more whole class debates/discussions
- Use more monologues/presentations on the lessons
- Concentrate more on grammar
- Concentrate more on vocabulary
- Implement more variable topics into the lessons
- Use more games

The learners stated that they were satisfied with the activities that were implemented throughout the study. They admitted noticing some minor changes on their own speaking performance, which was mainly visible on the fact that they became more confident. They stated that the numerous opportunities for speaking made them feel good and able to react more spontaneously. As for the suggestions for further improvements, they suggested using as many speaking activities in the lessons as possible. They suggested using discussions about real life topics on every lesson, as they considered that very important to be able to communicate on a daily basis. They also suggested more monologues and presentations, as they saw great benefits of self expressions. Monologues not only made them use the language without stopping for a longer span of time, they also made them think in the language, which they found very important. Another suggestion was implementing speaking activities that would focus solely on grammar or vocabulary, as they thought they lacked skills in these areas of speaking. They asked for more variability in the lessons, as they thought the topics provided by the textbooks did not prepare them well for the situations beyond the classroom. Lastly, they asked for using more games for a relaxed atmosphere.

\section{References}

Al-issa, A. S. \& Al-qubtan, R. (2010). Taking the floor: Oral presentations in EFL classrooms. TESOL Journal, 1 (2), 227-246.

Brown, H. D. (2004). Language assessment principles and classroom practice. New York: Pearson Education.

Bygate, M. (1987). Speaking. $1^{\text {st }}$ ed. Oxford: Oxford University Press.

Carter, R. \& Nunan, D. (2001). The Cambridge Guide to Teaching English to speakers of other languages. $1^{\text {st }}$ ed. New York: Cambridge University Press.

Fisher, D., Frey, N. \& Rothenberg, C. (2008). Content-Area Conversations: How to Plan Discussion-Based Lessons for Diverse Language Learners. ASCD.

Gani, S. A., Fajrina, D. \& Hanifa, R. (2015). Students' Learning Strategies for Developing Speaking Ability. Studies in English language and education, 2 (1), 16-28.

Gondová, D. (2013). Od gramatiky k hovoreniu. Bratislava.

Harmer, J. (2001). The practice of English language teaching. $3^{\text {rd }}$ ed. England: Longman.

Harmer, J. (2012). Essential teacher knowledge: core concepts in English language teaching. $1^{\text {st }}$ ed. Pearson Longman. 
Hinkel, E. (2010). Integrating the Four Skills: Current and Historical Perspectives. In R. B. Kaplan (Ed.), Oxford Handbook in Applied Linguistics (pp. 110-126). 2nd ed. Oxford University Press.

Howatt, A. P. R \& Smith, R. (2014). The history of teaching English as a foreign language, from a British and European perspective. In Language and History [online]. Available at: http://www.tandfonline.com/loi/ylhi20.

Kováčiková, E. \& Gajdáčová Veselá, K. (2016). Základy didaktiky cudzích jazykov. PF UKF v Nitre.

Levelt, W. J. M. (1989). Speaking: from intention to articulation. $1^{\text {st }}$ ed. MIT Press.

Long, M. H. \& Doughty, C. J. (2011). The Handbook of Language Teaching. John Wiley \& Sons.

Luoma, S. (2004). Assessing speaking. $1^{\text {st }}$ ed. Cambridge University Press.

Martinson, B. E. \& Chu, S. (2008). Impact of learning style on achievement when using course content delivered via a game-based learning object. In R. E. Ferdig (Ed.), Handbook of Research on Effective Electronic Gaming in Education Pennsylvania (pp. 478-488). IGI Global

Pauliková, K. (2017). Difficulties in Speech Production of Learners of English as a Foreign Language. In MMK 2017: International Masaryk conference for Ph.D. students and young researchers (pp. 665-672), Hradec Králové: Magnanimitas.

Pokrivčáková, S. (2013). Teaching techniques for modern teachers of English. Slovakia: ASPA.

Reid, E. \& Kováčiková, E. (2018). Creativity and Critical Thinking in Foreign language Teaching. Journal of Anglophone Studies 5 (1), 137-149.

Richards, J. C. (2008). Teaching Listening and Speaking - From Theory to Practice. Cambridge University Press.

Richards, J. C. \& Burns, A. (2012). The Cambridge Guide to Pedagogy and Practice in Second Language Teaching. Cambridge University Press.

Scrivener, J. (2005). Learning teaching: A guidebook for English language teachers. $2^{\text {nd }}$ ed. Macmillan ELT.

Thornbury, S. (1995). How to teach speaking. $1^{\text {st }}$ ed. Pearson Longman.

Ur, P. (1996). A course in language teaching: Practice and theory. $1^{\text {st }}$ ed. Cambridge: Cambridge University Press.

Acknowledgements:

The paper includes research results gained as a part of the project KEGA 006UKF-4/2017 Contrastive analysis as an effective supporting method of teaching English pronunciation at primary schools. 